\title{
Erratum to: Rice farming sustainability assessment in Bangladesh
}

\author{
Ranjan Roy $\cdot$ Ngai Weng Chan $\cdot$ Ruslan Rainis
}

Published online: 3 December 2013

(C) Springer Japan 2013

Erratum to: Sustain Sci

DOI 10.1007/s11625-013-0234-4

Unfortunately, the university that the authors affiliated to was published incorrectly in the original publication of the article.

The university name should be Universiti Sains Malaysia.

The online version of the original article can be found under doi:10.1007/s11625-013-0234-4.

R. Roy $(\bowtie) \cdot$ N. W. Chan $\cdot$ R. Rainis Department of Geography, School of Humanities,

Universiti Sains Malaysia, Penang, Malaysia

e-mail: ranjansau@yahoo.com

R. Roy

Department of Agricultural Extension and Information System,

Sher-e-Bangla Agricultural University, Dhaka, Bangladesh 